\title{
MRI predicts increased eligibility for sphincter preservation after CRT in low rectal cancer
}

Citation for published version (APA):

Krdzalic, J., Beets-Tan, R. G. H., Engelen, S. M. E., van Griethuysen, J., Lahaye, M. J., Lambregts, D. M. J., Bakers, F. C. H., Vliegen, R. F. A., Beets, G. L., \& Maas, M. (2020). MRI predicts increased eligibility for sphincter preservation after CRT in low rectal cancer. Radiotherapy and Oncology, 145, 223-228. https://doi.org/10.1016/j.radonc.2020.01.014

Document status and date:

Published: 01/04/2020

DOI:

10.1016/j.radonc.2020.01.014

Document Version:

Publisher's PDF, also known as Version of record

Document license:

Taverne

Please check the document version of this publication:

- A submitted manuscript is the version of the article upon submission and before peer-review. There can be important differences between the submitted version and the official published version of record.

People interested in the research are advised to contact the author for the final version of the publication, or visit the DOI to the publisher's website.

- The final author version and the galley proof are versions of the publication after peer review.

- The final published version features the final layout of the paper including the volume, issue and page numbers.

Link to publication

\footnotetext{
General rights rights.

- You may freely distribute the URL identifying the publication in the public portal. please follow below link for the End User Agreement:

www.umlib.nl/taverne-license

Take down policy

If you believe that this document breaches copyright please contact us at:

repository@maastrichtuniversity.nl

providing details and we will investigate your claim.
}

Copyright and moral rights for the publications made accessible in the public portal are retained by the authors and/or other copyright owners and it is a condition of accessing publications that users recognise and abide by the legal requirements associated with these

- Users may download and print one copy of any publication from the public portal for the purpose of private study or research.

- You may not further distribute the material or use it for any profit-making activity or commercial gain

If the publication is distributed under the terms of Article $25 \mathrm{fa}$ of the Dutch Copyright Act, indicated by the "Taverne" license above, 


\title{
MRI predicts increased eligibility for sphincter preservation after CRT in low rectal cancer
}

\author{
Jasenko Krdzalic a,b, Regina G.H. Beets-Tan ${ }^{\text {a,c }}$, Sanne M.E. Engelen ${ }^{\text {d }}$, Joost van Griethuysen ${ }^{\text {a }}$, Max J. Lahaye ${ }^{\text {, }}$, \\ Doenja M.J. Lambregts ${ }^{a}$, Frans C.H. Bakers ${ }^{e}$, Roy F.A. Vliegen ${ }^{f}$, Geerard L. Beets ${ }^{\text {c,g }}$, Monique Maas ${ }^{\mathrm{a}, *}$

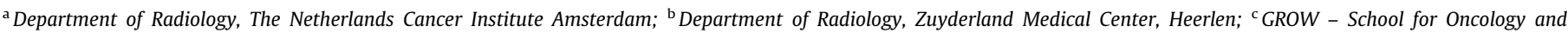

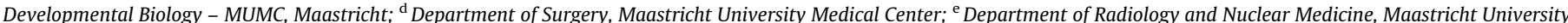

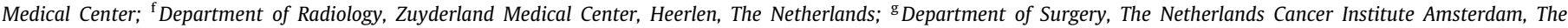 \\ Netherlands
}

\section{A R T I C L E I N F O}

\section{Article history:}

Received 11 June 2019

Received in revised form 25 September 2019

Accepted 12 January 2020

Available online 15 February 2020

\section{Keywords:}

Rectal cancer

MRI

Sphincter preservation

Response

\begin{abstract}
A B S T R A C T
Chemoradiation increases the eligibility for sphincter preservation in low rectal cancer, as assessed by MRI.

Introduction: We evaluated whether MRI can predict sphincter preservation after chemoradiation (CRT), and whether the feasibility of sphincter preservation increases after CRT, when compared with MRI before neoadjuvant treatment.

Methods: 85 patients with low rectal tumour ( $\leq 5 \mathrm{~cm}$ from anorectal junction (ARJ)) were included. Radiologist and a surgeon measured the tumour distance to ARJ, and assigned confidence level scores (CLS) for the feasibility of sphincter preserving surgery on MRI. Reference standard was the type of surgery, sphincter preserving vs. non-preserving.

Results: Tumour distance from the ARJ increased after CRT by $9 \mathrm{~mm}(p<0.001)$. Eligibility for sphincter preservation increased by $21 \%$ for the radiologist and $25 \%$ for the surgeon, based on CLS. Cut-off for distance to the ARJ after CRT was $28 \mathrm{~mm}$, aiming for optimal specificity.

Diagnostic performance after CRT based on CLS yielded an AUC of 0.81 [95\%CI $0.70-0.91$ ] for the radiologist and 0.82 [95\%CI 0.72-0.92] for the surgeon $(p=0.78)$. AUCs for tumour distance to the ARJ were 0.85 [95\%CI 0.77-0.94] and 0.84 [95\%CI 0.75-0.94], respectively $(p=0.84)$.

Interobserver agreement for CLS was moderate before CRT (K $0.51 ; 95 \% \mathrm{CI} 0.36-0.66$ ) and after (K 0.54 ; 95\%CI 0.39-0.69). Measurement of tumour distance to ARJ showed good agreement before (ICC 0.76; $95 \%$ CI $0.65-0.84$ ) and after CRT (ICC $0.77 ; 95 \%$ CI $0.66-0.84$ ).

Conclusion: MRI can be a valuable adjunct in the decision making for sphincter preservation after CRT, with distance from the tumour to the ARJ as an accurate and reliable factor. CRT increases the tumour distance to the ARJ, leading to an estimated increase of sphincter preserving surgery in up to $21-25 \%$ of patients.
\end{abstract}

(c) 2020 Elsevier B.V. All rights reserved. Radiotherapy and Oncology 145 (2020) 223-228
It is generally accepted that regardless of the type of surgery in rectal cancer, the primary goal of surgical treatment remains oncologic cure, while preservation of the sphincter function and avoidance of a colostomy are important secondary goals for the patient [1]. The feasibility of oncologically safe sphincter preservation is primarily determined by tumour characteristics (e.g. distance of the tumour from the anorectal junction, fixation of the tumour, preoperative tumour size and stage), but also by patient related factors, such as patient preference, obesity, previous history of abdominal surgery and preoperative continence [2]. Additionally,

\footnotetext{
* Corresponding author at: Department of Radiology, The Netherlands Cancer Institute Amsterdam, P.O. Box 90203, 1006 BE Amsterdam, The Netherlands.

E-mail address: moniquemaas@live.nl (M. Maa.
}

it also depends on the experience of the surgeon [3]. Surgical advances in the 20th century led to successful application of low anterior resection (LAR) for cancers of the middle and upper rectum, while reserving abdominoperineal resection for cancers below this level [4]. Later on, application of neoadjuvant (chemo) radiotherapy in rectal cancer not only reduced rates of local recurrence, but also increased the chance for sphincter preservation instead of abdominoperineal excision in low rectal cancer, when compared to patients receiving chemoradiation after surgery [5]. However, a recent review found no positive effect of neoadjuvant treatment on the rate of sphincter preservation, which is conflicting with the previous assumption [6].

In a previous study it was shown that MRI can accurately predict the feasibility of sphincter preservation in patients with distal 
rectal cancer that were not treated with CRT [7]. The measurement of the tumour distance to the anorectal junction (ARJ) on MRI (distance from the ARJ to the distal part of the tumour) yielded the best results to predict surgical sphincter preservation. The aim of this study is to evaluate whether MRI can predict sphincter preservation after chemoradiation (as measured by tumour distance to the ARJ and by assessment of a radiologist and a surgeon with confidence level scores), and additionally, to evaluate by MRI whether the feasibility of sphincter preservation increases after chemoradiation, when compared with MRI before neoadjuvant treatment.

\section{Material and methods}

Patients were selected from a prospectively collected database of patients who underwent MRI for rectal cancer at the Maastricht University Medical Center between February 2003 and December 2014. Inclusion criteria were: [1] biopsy proven rectal adenocarcinoma [2], tumour located in the distal rectum with the lower border located $<5 \mathrm{~cm}$ from the ARJ on MRI [3], treatment with neoadjuvant chemoradiation (CRT) and surgery after a long waiting interval to obtain downstaging and downsizing [4], availability of restaging after CRT with MRI before surgery, and [5] a minimum follow-up time of 2 years.

Patients were excluded when the histology report was missing. Furthermore, patients with a palliative treatment, multiple primary colorectal tumours, synchronous metastasis at primary diagnosis and patients who had a transanal endoscopic microsurgery (TEM) resection were excluded. Due to the retrospective nature of the study informed consent was waived by the Institutional Review Board.

\section{MRI}

MRI was performed on 1.5 T MR units (Intera (Achieva) or Ingenia system, Philips Medical Systems, Best, The Netherlands). Patients were placed in supine position, feet first, and patients received $20 \mathrm{mg}$ of scopolamine butylbromide (Buscopan, Boehringer Ingelheim, Germany) in case of anticipated bowel movement artifacts on the sagittal planning scan (first part of the study period) or routinely (final part of the study period). Phased-array multichannel coils were used for signal reception. The MR protocol consisted of 2D T2-weighted fast spin echo (FSE) sequences in three orthogonal planes in the majority of the patients. In a small subset only two T2W series were available (sagittal and axial perpendicular to the tumour axis). Parameters were: TR/TE $3427 / 150 \mathrm{~ms}$, 3NSA, voxel size of $0.8 \times 1.1 \times 3-5 \mathrm{~mm}$, 22 slices for the sagittal images and TR/TE 9558/130 ms, 3NSA, voxel size of $0.8 \times 1.1 \times 3-5 \mathrm{~mm}, 30$ slices for the axial and coronal images. The axial images were angled perpendicular to the tumour axis, the coronal images were angled parallel to the tumour axis.

\section{MRI evaluation}

The MR images acquired before and after CRT were assessed by 2 independent readers: [1] a radiologist specialised in MR imaging of the rectum (M.M. 9 years of experience), and [2] a gastrointestinal surgeon with prior reading experience (S.M.M.E. 4 years of experience) of rectal MRI in a research setting. Evaluation of probability of sphincter preservation and measurement of tumour distance to the ARJ were performed at T2W-MRI. Axial diffusion weighted images (DWI) were available in all patients at the postCRT MRI for reference. The surgeon was trained in assessment of MR-images, including DWI. Readers were allowed to use DWI as an additional tool for assessment of the location of residual tumour, when patients showed a very good response and it was difficult to appreciate the residual tumour on T2W-MRI. DWI was not used for the assessment of tumour height or assessment of chance for sphincter preservation.

Readers qualitatively assessed feasibility of sphincter preservation before and after CRT by use of confidence level scores, ranging from 0 to 4 ( 0 = sphincter preservation definitely not possible, and 4 = definitely possible to preserve the sphincter). Feasibility of sphincter preservation was determined by a subjective assessment of the tumour relation to the $\mathrm{m}$. levator ani and anal sphincter, and the feasibility of obtaining a surgical margin that would still allow for sphincter preservation.

Tumour distance to the ARJ was quantitatively measured as the distance $(\mathrm{mm})$ from the anorectal junction to the most distal part of the tumour (see Supplementary figure 1) [8]. All scores and measurements were separately performed on the pre-CRT and postCRT images for each patient. In case of a possible complete response of tumour after neoadjuvant CRT, the readers were instructed to measure the distance from the ARJ to the most distal part of fibrosis/scar in the rectal wall. The readers were blinded to the type of surgery the patients underwent, the radicality of resection, and the follow-up information regarding recurrence. The surgeon that participated in this study did not perform any of the surgical resections within the study population.

\section{Reference standard}

The type of rectal surgery, the completeness of resection and absence or presence of local recurrence during follow-up were used as the standard of reference. Sphincter preservation was defined as surgery consisting of low anterior resection (LAR) or Hartmann's procedure with complete surgical margins and absence of a local luminal recurrence during follow-up. Unsuccessful sphincter preservation was defined as an abdominoperineal resection (APR), incomplete resection after low anterior or Hartmann's resection with a positive distal or circumferential margin, or an anastomotic recurrence during follow-up of at least 2 years. Definition does not include an assessment or evaluation of sphincter function, as this study focusses on the measurement and possible change of tumour distance to the ARJ after CRT, as a factor determining the feasibility of sphincter preservation.

\section{Statistical analysis}

Descriptive statistics were used to assess baseline characteristics. With the continuous variable tumour height and the confidence levels for sphincter preservation, receiver operator characteristics (ROC) curves were constructed and the Areas Under the Curves (AUCs) were calculated to predict sphincter preservation. Corresponding accuracy parameters (sensitivity, specificity, positive predictive value and negative predictive value) were calculated for the confidence level scores, which were dichotomized with a cut-off between confidence level 2 and 3 as determined before the onset of the study. The optimal cut-off for the tumour distance to the ARJ was extracted from the ROC curve analyses aiming for high specificity, and corresponding accuracy parameters were calculated. AUCs were compared between readers by the method of Hanley et al. [9].

For the assessment of interobserver reproducibility, quadratic weighted kappa statistics were used for the confidence level scores. For the continuous variable of tumour distance to the ARJ, Intraclass Correlation Coefficients were calculated and Bland Altman plots were constructed. All analyses were performed with Statistical Package for the Social Sciences $\left(\right.$ IBM $^{\circledR}$ SPSS $^{\circledR}$ Statistics Version 23; Release 23.0.0) and Stata 11.0, $p$-values of $\leq 0.05$ were considered significant. 


\section{Results}

In total, 676 patients with rectal cancer (between April 2003 and June 2015) were identified of which 85 patients were eligible for the inclusion (see Supplementary figure 2). Baseline characteristics of the included patients are shown in table 1. Median patient age at surgery was 66 years [range 44-87], and 65\% were male. Median interval between the baseline MRI and the restaging MRI was 16 weeks [range 12-30], and the median interval between the restaging MRI and surgery was 2 weeks [range 0-10]. Of the 85 patients, 55 had a LAR $(n=41)$ or Hartmann's procedure ( $n=14)$ and remained without recurrence; these patients constituted the 'sphincter preservation' group. The remaining 30 patients had an APR ( $n=29)$, or LAR followed by an anastomotic recurrence $(n=1)$ at the anastomosis after 10 months of follow-up; these patients constituted the 'no sphincter preservation' group. Median follow-up was 4.9 years [range 2.1-11.1 years].

Before CRT 44 (52\%) of the 85 patients were deemed eligible for sphincter preservation by the radiologist, and 27 (32\%) by the surgeon, based on a confidence level score of $\geq 3$ (sphincter preservation probably or definitely feasible). After CRT, this number increased to $62(73 \%)$ and 48 (56\%), respectively (Fig. 1a). The increase was $21 \%$ for the radiologist and $25 \%$ for the surgeon.

Mean distance to the ARJ of the tumour before CRT was $20.5 \mathrm{~mm}$ (SD $\pm 15.4 \mathrm{~mm}$ ) for the radiologist and $20.6 \mathrm{~mm}$ ( $\mathrm{SD} \pm 15.7 \mathrm{~mm}$ ) for the surgeon. After the CRT, mean distance was $29.1 \mathrm{~mm}(\mathrm{SD} \pm 18.5 \mathrm{~mm}$ ) for the radiologist and $29.6 \mathrm{~mm}$ (SD $\pm 19.0 \mathrm{~mm}$ ) for the surgeon (Fig. 1b). The increase in tumour distance to the ARJ of $9 \mathrm{~mm}$ after CRT, compared to the baseline MRI, was statistically significant for both readers $(p<0.001)$.

Table 1

Demographics of the study population. TNM 7 criteria were used for tumour assessment.

\begin{tabular}{|c|c|}
\hline Variable & $n=85$ patients \\
\hline Median age & $66[44-87]$ \\
\hline \multicolumn{2}{|l|}{ Sex } \\
\hline Male & $54(63)$ \\
\hline Female & $31(37)$ \\
\hline \multicolumn{2}{|l|}{ Treatment variables } \\
\hline Interval first MRI - surgery & 19 weeks [13-35] \\
\hline Interval restaging MRI - surgery & 2 weeks $[0-10]$ \\
\hline Sphincter preserving resection & $56(66)$ \\
\hline Radical resection & $84(99)$ \\
\hline Anastomosis recurrence & $1(1)$ \\
\hline \multicolumn{2}{|l|}{ T-stage at diagnosis } \\
\hline $\mathrm{T} 1$ & 0 \\
\hline $\mathrm{T} 2$ & $7(8)$ \\
\hline T3 & $69(81)$ \\
\hline $\mathrm{T} 4$ & $9(11)$ \\
\hline \multicolumn{2}{|l|}{$\mathrm{N}$-stage at diagnosis } \\
\hline NO & $9(11)$ \\
\hline N1 & $25(29)$ \\
\hline $\mathrm{N} 2$ & $51(60)$ \\
\hline \multicolumn{2}{|l|}{ Pathological T-stage } \\
\hline T0 & $8(9)$ \\
\hline $\mathrm{T} 1$ & $6(7)$ \\
\hline $\mathrm{T} 2$ & $30(35)$ \\
\hline T3 & $40(47)$ \\
\hline $\mathrm{T} 4$ & $1(1)$ \\
\hline \multicolumn{2}{|l|}{ Pathological N-stage } \\
\hline NO & $69(81)$ \\
\hline $\mathrm{N} 1$ & $12(14)$ \\
\hline N2 & $4(5)$ \\
\hline
\end{tabular}

Demographics of the study population. TNM 7 criteria were used for tumou assessment.

Numbers between [ ] indicate ranges and between () percentages. (a)

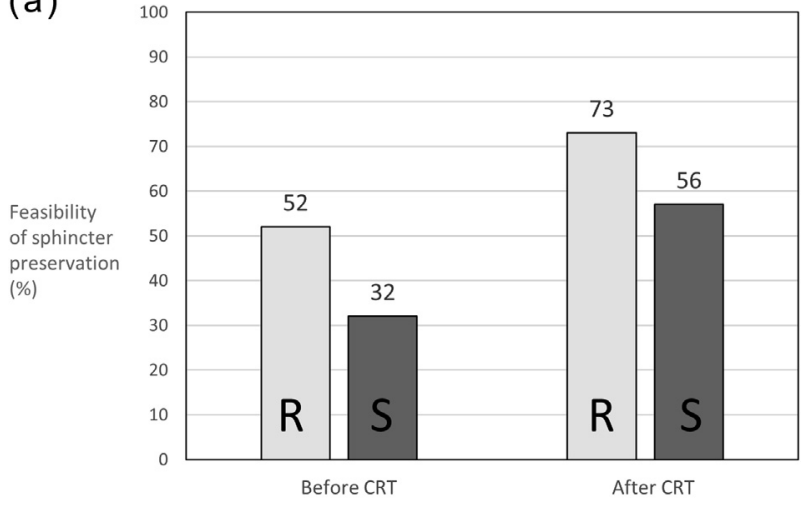

(b)

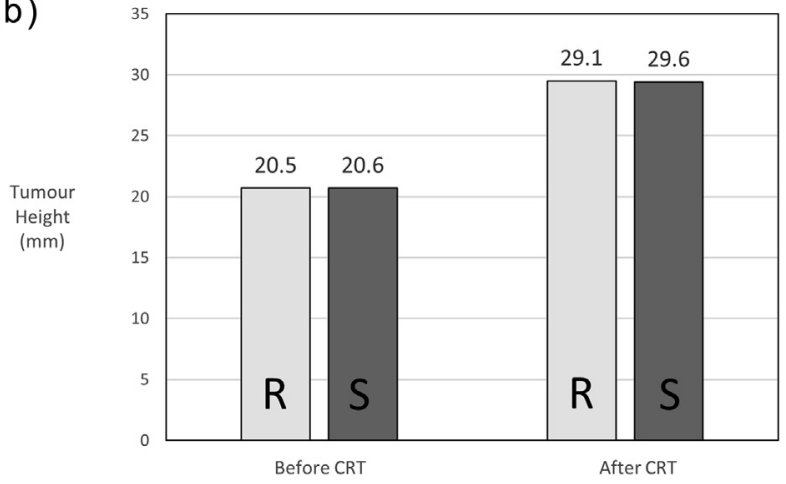

Fig. 1. (A) Feasibility of sphincter preservation defined as a confidence level score of 3 or 4 (i.e. probably or definitely feasible) increased significantly after neoadjuvant chemoradiation. Increase was 21 and $25 \%$ when assessed by the radiologist and the surgeon, respectively. (B) Tumour height (distance from the ARJ to the distal tumour margin) increased significantly after neoadjuvant chemoradiation, with an increase of $9 \mathrm{~mm}$. (R) Radiologist, (S) Surgeon.

Prediction of the feasibility of sphincter preservation after CRT based on the visual confidence level scores yielded an AUC of 0.81 [95\%CI 0.70-0.91] for the radiologist and an AUC of 0.82 [95\%CI 0.72-0.92] for the surgeon ( $p=0.78$ ), see Fig. 2. For tumour distance to the ARJ, the AUC for prediction of surgical sphincter preservation was 0.85 [95\%CI $0.77-0.94]$ for the radiologist and 0.84 [95\%CI $0.75-0.94]$ for the surgeon $(p=0.84)$.

Table 2 shows the diagnostic parameters for both readers to predict surgical sphincter preservation. For the confidence level score, the radiologist's and surgeon's sensitivity was $91 \%$ and $77 \%$, and specificity was $60 \%$ and $80 \%$, respectively. The optimal cut-off for tumour distance to the ARJ, as derived from the ROC curve, was $28 \mathrm{~mm}$. With this cut-off the sensitivity for the radiologist was $69 \%$ vs. $75 \%$ for the surgeon. By use of the cut-off of $28 \mathrm{~mm}$ specificity was $90 \%$ for the radiologist and $80 \%$ for the surgeon

For the visual confidence level, agreement between the radiologist and surgeon was moderate before CRT (K 0.51; 95\%CI 0.360.66 ) and moderate (K 0.54; 95\% CI 0.39-0.69) after CRT. Measurement of distance to the ARJ before and after CRT showed a good agreement with an ICC of 0.76 (95\%CI $0.65-0.84)$ before and an ICC of 0.77 (95\%CI 0.66-0.84) after CRT between readers. Bland Altman plots, before and after CRT, are shown in Fig. 3.

\section{Discussion}

Primarily, the surgeon's decision on sphincter preservation is determined by digital rectal examination that provides information about the feasibility of obtaining a free margin by palpating 


\section{Confidence level}

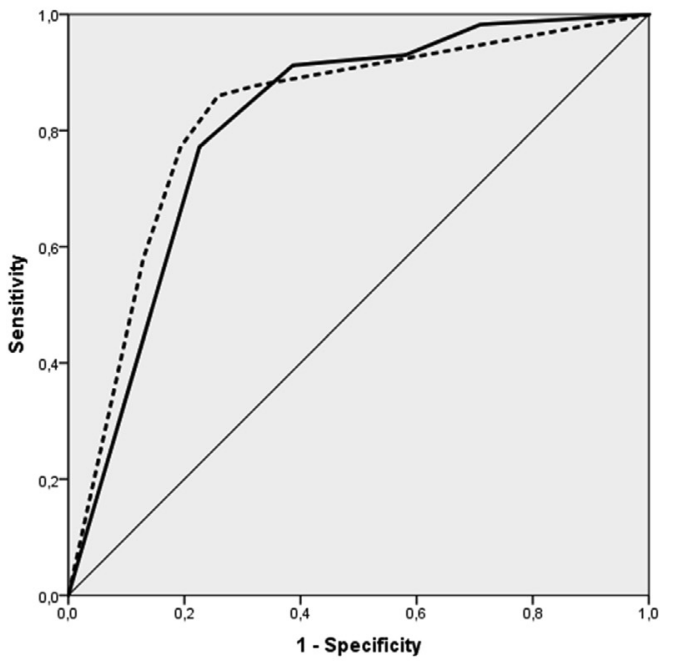

Tumour height

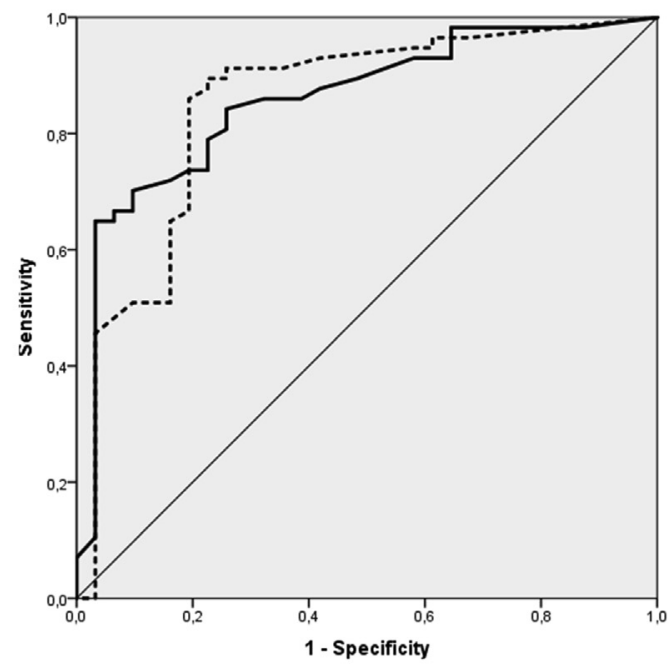

(-) Radiologist, (---) Surgeon.

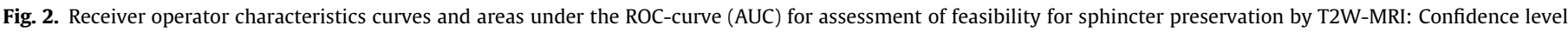

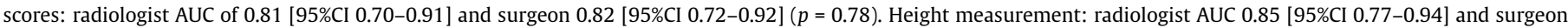
AUC 0.84 [95\%CI 0.75-0.94] $(p=0.84)$.

Table 2

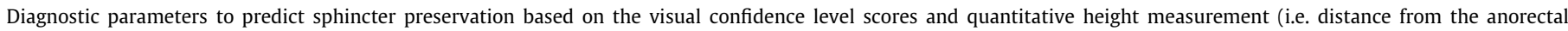
junction). For the height measurement an optimal cut-off point of $28 \mathrm{~mm}$ was selected, aiming to optimise specificity.

\begin{tabular}{|c|c|c|c|c|}
\hline & \multicolumn{2}{|c|}{ Confidence Level } & \multicolumn{2}{|c|}{ Height (cut-off $28 \mathrm{~mm}$ ) } \\
\hline & Radiologist & Surgeon & Radiologist & Surgeon \\
\hline Sensitivity & $91(83-96)$ & $77(68-82)$ & $69(61-73)$ & $75(66-80)$ \\
\hline Specificity & $60(46-70)$ & $80(65-91)$ & $90(75-97)$ & $80(65-91)$ \\
\hline PPV & $81(74-86)$ & $88(78-94)$ & $93(82-98)$ & $87(77-94)$ \\
\hline NPV & $78(60-91)$ & $65(53-74)$ & $61(51-66)$ & $63(51-72)$ \\
\hline
\end{tabular}

$\mathrm{PPV}=$ positive predictive value, $\mathrm{NPV}=$ negative predictive value.

Numbers between () indicate 95\% Confidence Interval.

the distance from tumour to anal sphincter. Our study shows that MRI can be a helpful additional tool to predict surgical sphincter preservation after CRT in low rectal cancer ( $\leq 5 \mathrm{~cm}$ from the ARJ). Secondarily, both the radiologist and the GI surgeon had a good diagnostic performance for both subjective assessment and objective measurements of the tumour distance to the ARJ. However, assessment based on tumour distance was more accurate than the subjective confidence level assessment and showed a better inter-observer reproducibility for both readers. The optimal cutoff value for distance to the ARJ was $28 \mathrm{~mm}$, providing a high specificity for prediction of sphincter preservation and thus leading to a low risk of falsely predicting sphincter preservation. After CRT, the estimated feasibility of sphincter preservation increased by 21$25 \%$. This suggests that CRT increases the chance of sphincter preservation, when assessed by MRI.

\section{Assessment of feasibility of sphincter preservation on MRI}

Currently, no predetermined criteria exist for the assessment of sphincter preservation by MRI. The decision to preserve the sphincter is made by the operating surgeon together with the patient and depends on other factors besides tumour height (e.g. weight and preoperative sphincter function). Tumour distance to the ARJ as measured on MRI yielded a good diagnostic performance to assess the feasibility of surgical sphincter preservation for both a radiologist and a surgeon. The optimal cut-off for surgical sphincter preservation was $28 \mathrm{~mm}$, which is twice as high as the optimal cutoff in a non-CRT setting as determined in a previous study (14 mm) [7]. This could be explained by the presence of fibrosis after CRT, necessitating a larger surgical margin (upon palpation during surgery) relative to the residual tumour, compared to patients without neoadjuvant CRT.

When compared to the subjective confidence level scores, distance to the ARJ measurement yielded a higher diagnostic performance, with a higher AUC for both readers and a large increase in specificity for the radiologist (60\% to $90 \%$ ). A high specificity is desirable as the reader would prefer to err on the safe side that sphincter preservation is unlikely based on MR images alone, than to be overly optimistic and unexpectedly needing to perform an APR with permanent colostomy. Apparently, making a subjective assessment of the feasibility of sphincter preservation is more challenging and objective measurements are more reliable, which is supported by the higher interobserver agreement for height than for confidence level scores (ICC 0.77 vs. weighted kappa 0.54). From a radiological point of view, it suffices to report on the distance of the lower pole of the tumour to the ARJ, so that the surgeon can use this for his decision on sphincter preservation during patient counselling. Also, this information can be used in multidisciplinary team meetings to discuss surgical options.

The difference in sensitivity when using confidence level scores between the radiologist and surgeon can probably be explained by the reading surgeon's more conservative interpretation and reluc- 
(a)

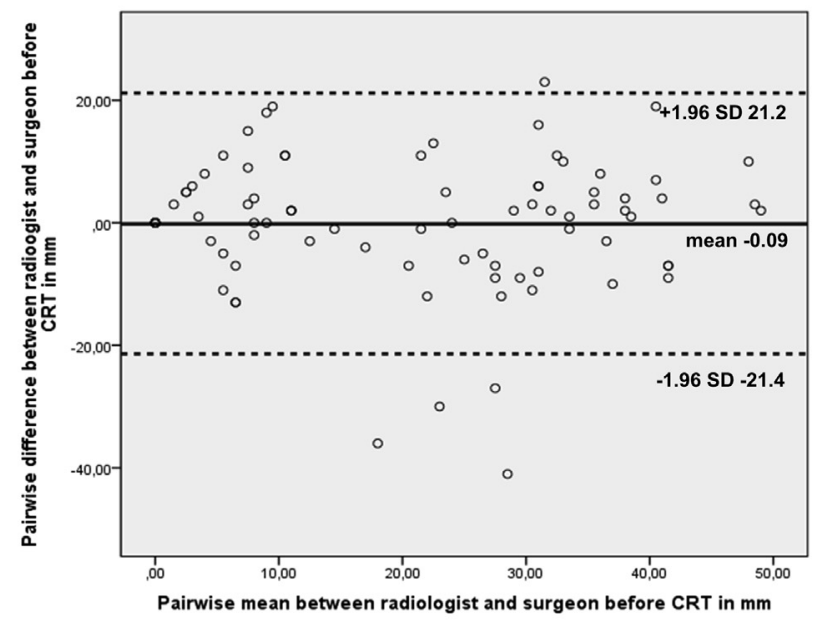

(b)

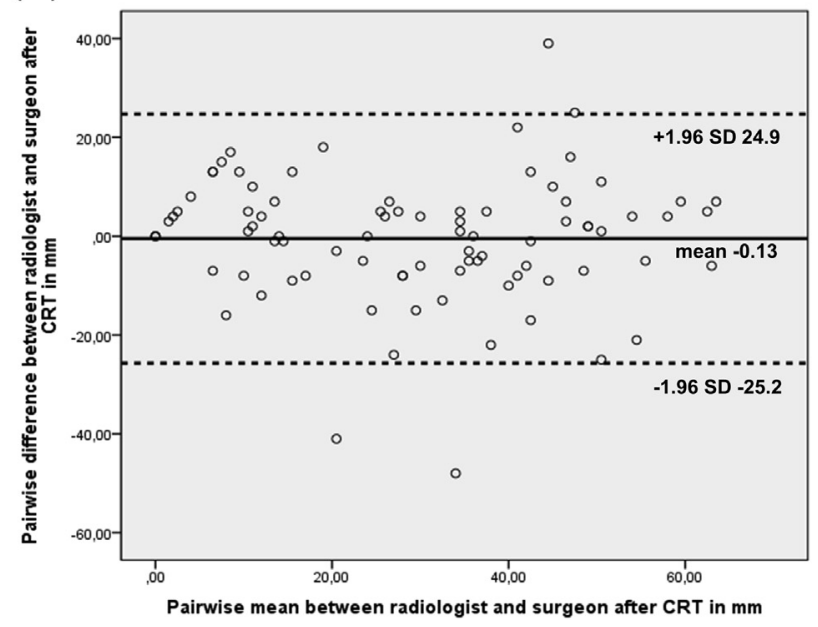

Fig. 3. Bland-Altman plots showing measured tumour height, before (A) and after (B) CRT. Solid line on the y-axis indicates the mean difference between the readers. Dashed lines indicate 95\% limits of agreement. tance towards prediction of sphincter preservation based on imaging only. The presence of fibrosis might have exaggerated this effect (Fig. 4). Lack of this information could be a probable explanation of the higher number of false negative predictions in the surgeon's assessment. However, this more conservative approach led to a higher specificity for the surgeon compared to the radiologist ( $80 \%$ vs. $60 \%$, respectively). Inclusion of a surgeon for this assessment shows that it is feasible for surgeons to use the MRI as a part of patient counselling for sphincter preservation options and that they do not solely need to rely on the measurement and evaluation of the radiologist. As a surgeon can combine clinical factors with the MRI findings, he will be able to provide a more accurate insight into the sphincter preservation possibilities, which will help managing patient expectations.

\section{CRT effect on the feasibility of sphincter preservation}

The results of our study suggest that CRT does lead to an increase in sphincter preservation, which is supported by earlier studies on the effect of CRT (without use of MRI) on sphincter preservation $[10,11]$. On the contrary, two different Cochrane reviews failed to show a significant increase in sphincter preservation rate due to CRT $[6,12]$. A hypothesis to explain this difference is that in the studies included in the Cochrane reviews surgeons could have performed TME based on the original stage and location of the tumour. In our study cohort restaging MRIs were used to adapt the surgical planning according to response. Only one other study by Ihn et al. evaluated the increase of likelihood of sphincter preservation based on changes in tumour distance from to the ARJ, using pelvic MRI [13]. The authors showed an increase in distance of only $3.1 \mathrm{~mm}$ after CRT, but they did find that an APR was performed more often in the group without increase than in patients with increase of tumour distance to the ARJ (23 vs. 13\%). A substantial part of the patients underwent intersphincteric resection (31\%), which suggests that Ihn et al. evaluated a subselection of patients with a very low (ultralow) rectal tumour. In the group of ultralow rectal tumours with sphincter involvement before CRT it is unlikely that sphincter preservation will increase after CRT (fibrosis will remain visible in the anal canal). Therefore, Ihn et al. might underestimate the increase in sphincter preservation by CRT in low rec-
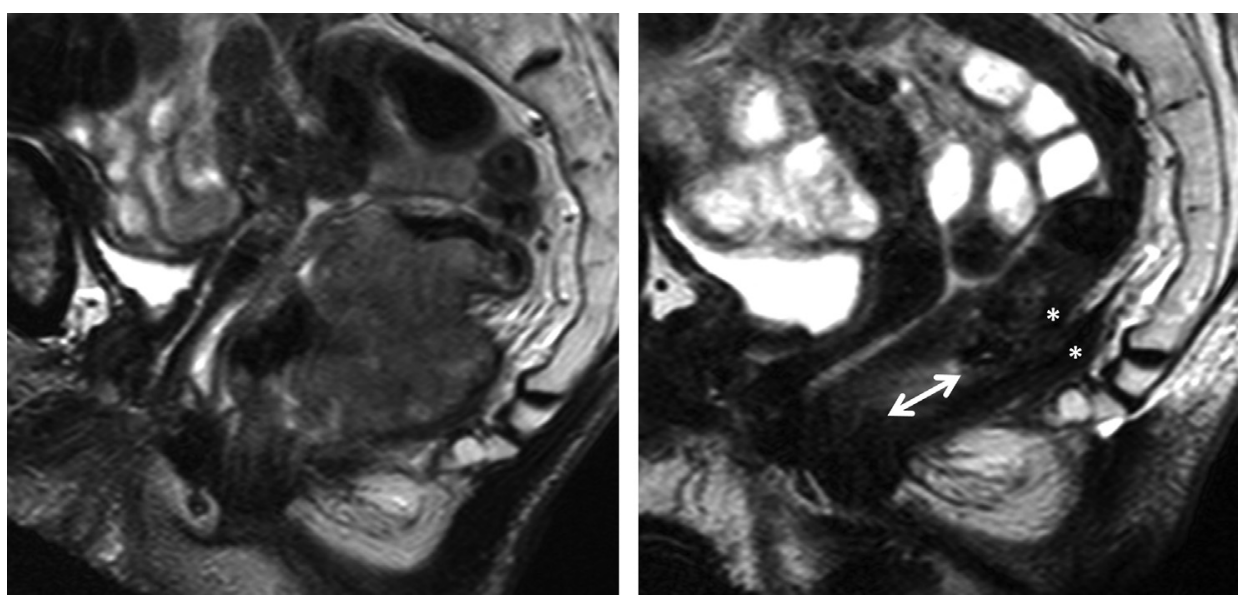

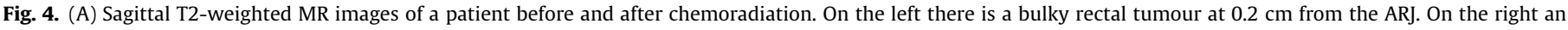

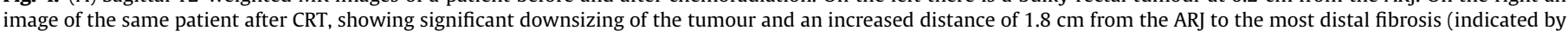

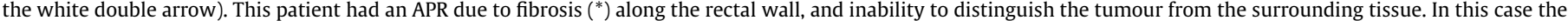

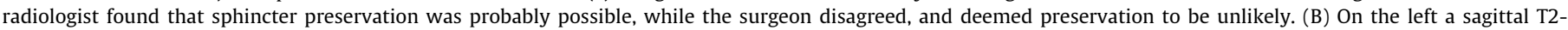

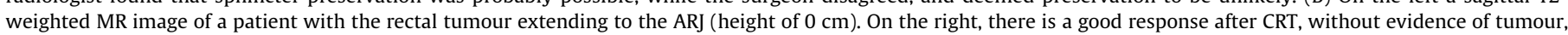

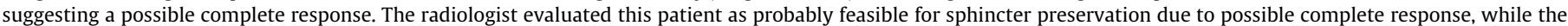
surgeon thought sphincter preservation was definitely not possible. This patient had an APR, but no tumour was found on pathology exam. 
tal cancer in general. Additionally, they did not take into account the completeness of the resection in their reference standard. So far, although an increase in feasibility of sphincter preservation after CRT seems compelling, there is still lack of sound evidence to legitimate this general assumption.

\section{Limitations}

There are some limitations to our study. First, during the inclusion period different surgeons performed the TMEs and could have taken different decisions regarding sphincter preservation. Second, one of the readers was a surgeon with prior experience in MRI reading, which is not common practice. GI surgeons increasingly read MRIs as a preparation for surgery and our results show that surgeons can achieve a good level of experience in reading rectal cancer MRI. With the results of this study we like to encourage colorectal surgeons to evaluate the MRI when consulting with the patient about chances for sphincter preservation. Third, there is no gold standard to predict sphincter preservation before surgery. Different factors influence the surgical decision making, such as patient and institutional preferences, limiting the accuracy of predictability based on MRI alone. Still, knowledge about feasibility of sphincter preservation based on MRI apparently can be of value in patient counselling. Last, for the assessment of successful sphincter preservation sphincter function was not incorporated in our outcomes.

MRI can be a valuable adjunct in the decision making for sphincter preservation after CRT in low rectal cancer. The measured distance from the lower margin of the tumour to the anorectal junction is an accurate and reliable factor. In the present series the reconstructed optimal cut-off distance in a post-CRT setting is $28 \mathrm{~mm}$. Chemoradiation increases the distance of the tumour to the ARJ, leading to an estimated increase of sphincter preserving surgery in up to $21-25 \%$ of patients.

\section{Conflicts of interest}

None.

\section{Appendix A. Supplementary data}

Supplementary data to this article can be found online at https://doi.org/10.1016/j.radonc.2020.01.014.

\section{References}

[1] Bordeianou L, Maguire LH, Alavi K, Sudan R, Wise PE, Kaiser AM. Sphinctersparing surgery in patients with low-lying rectal cancer: techniques, oncologic outcomes, and functional results. J Gastroint Surg 2014;18:1358-72.

[2] Howard JH, Gonzalez Q Arnoletti JP, Russo S, Fiveash JB, Bland KI, et al. Prognostic factors and preoperative radiation therapy associated with sphincter preservation in patients with resectable rectal cancer. Am J Surg 2008;195:239-43.

[3] Temple LK, Romanus D, Niland J, Veer AT, Weiser MR, Skibber J, et al. Factors associated with sphincter-preserving surgery for rectal cancer at national comprehensive cancer network centers. Ann Surg 2009;250:260-7.

[4] Dixon CF. Anterior resection for malignant lesions of the upper part of the rectum and lower part of the sigmoid. Ann Surg 1948;128:425-42.

[5] Sauer R, Becker H, Hohenberger W, Rodel C, Wittekind C, Fietkau R, et al. Preoperative versus postoperative chemoradiotherapy for rectal cancer. N Engl J Med 2004;351:1731-40.

[6] McCarthy K, Pearson K, Fulton R, Hewitt J. Pre-operative chemoradiation for non-metastatic locally advanced rectal cancer. Cochrane Database Syst Rev 2012;12:Cd008368.

[7] ECR 2016 Book of Abstracts - B - Scientific Sessions and Clinical Trials in Radiology. Insights Imaging 2016;7(1):162-465.

[8] Beets-Tan RGH, Lambregts DMJ, Maas M, Bipat S, Barbaro B, Curvo-Semedo L, et al. Magnetic resonance imaging for clinical management of rectal cancer: Updated recommendations from the 2016 European Society of Gastrointestinal and Abdominal Radiology (ESGAR) consensus meeting. Eur Radiol 2017.

[9] Hanley JA, McNeil BJ. A method of comparing the areas under receiver operating characteristic curves derived from the same cases. Radiology 1983;148:839-43.

[10] Gerard JP, Chapet O, Nemoz C, Hartweig J, Romestaing P, Coquard R, et al. Improved sphincter preservation in low rectal cancer with high-dose preoperative radiotherapy: the lyon R96-02 randomized trial. J Clin Oncol 2004;22:2404-9.

[11] Rullier E, Goffre B, Bonnel C, Zerbib F, Caudry M, Saric J. Preoperative radiochemotherapy and sphincter-saving resection for T3 carcinomas of the lower third of the rectum. Ann Surg 2001;234:633-40.

[12] Ceelen WP, Van Nieuwenhove Y, Fierens K. Preoperative chemoradiation versus radiation alone for stage II and III resectable rectal cancer. Cochrane Database Syst Rev 2009;1. Cd006041.

[13] Ihn MH, Kim YH, Kim DW, Oh HK, Lee SY, Park JT, et al. Effects of preoperative chemoradiotherapy on the likelihood of sphincter preservation surgery in locally advanced distal rectal cancer: a longitudinal study based on pelvic magnetic resonance imaging. Ann Surg Oncol 2015;22:2159-67. 